\title{
Inhibitive Properties and Quantum Chemical Calculations of a New Synthesized Schiff Base 1-[(3hydroxyphenylamino) methylene]-naphtalen-2-one for XC48 in Hydrochloric Acid Solution
}

\author{
Bouzidi Leila ${ }^{1 . *}$, Haffar Djahida ${ }^{1}$, Abdi Djamila ${ }^{2}$, Mouzali Saida $^{1}$, and Chafaa Salah ${ }^{1}$ \\ ${ }^{1}$ Laboratory of Electrochemistry of Molecular Materials and Complexes (LEMMC), Department of \\ Engineering Process, Faculty of Technology, University of Setif 1, Algeria \\ ${ }^{2}$ Laboratoire d'énergétique et d'électrochimie du solide, Department of Engineering Process, Faculty \\ of Technology, University of Setif 1, Algeria \\ *E-mail: 1eila.8207@yahoo.fr
}

doi: $10.20964 / 2018.07 .23$

Received: 16 January 2018 / Accepted: 2 April 2018 / Published: 5 June 2018

\begin{abstract}
A new Schiff base derived from o-hydroxy aromatic aldehyde, namely 1-[(3-hydroxyphenylamino) methylene]-naphtalen-2-one (L), was synthesized and characterized by X-ray crystallographic technique. It is then evaluated as inhibitor on the corrosion of mild steel XC48 in a 1M hydrochloric acid solution. The study was carried out using weight loss, polarization, electrochemical impedance spectroscopy and Quantum chemical. At constant temperature, the corrosion rate decreases with increasing the inhibitor content. A maximum inhibition efficiency of $78.3 \%$ was obtained at $10^{-3} \mathrm{M}$. However, the increase in temperature leads to an increase in the corrosion rate of steel. Calculation and estimation of thermodynamic parameters $\mathrm{E}_{\mathrm{a}}, \Delta \mathrm{H}^{\circ}{ }_{\text {ads }}, \Delta \mathrm{S}_{\text {ads }}^{\circ}$, and $\Delta \mathrm{G}_{\text {ads }}^{\circ}$ help in determining the inhibition mechanism of the Schiff base. It was found that Schiff base acted as mixed type inhibitor with predominant cathodic inhibition and adsorbs according to Langmuir adsorption isotherm model. Morphological surface aspect has been investigated using optical microscope. Quantum chemical calculations study corroborates experimental results.
\end{abstract}

Keywords: Synthesis; Mild steel; Weight loss; Adsorption; Polarization; Impedance

\section{$\underline{\text { FULL TEXT }}$}

(C) 2018 The Authors. Published by ESG (www.electrochemsci.org). This article is an open access article distributed under the terms and conditions of the Creative Commons Attribution license (http://creativecommons.org/licenses/by/4.0/). 